\title{
Influence of a Ceramic Substrate on Aqueous Precipitation and Structural Evolution of Alumina Nano-Crystalline Coatings
}

\author{
Marie Mahé and Peter Reynders ${ }^{\dagger}$ \\ Department of Pigments, Merck KGaA, Darmstadt 64271, Germany
}

Alain Demourgues and Jean-Marc Heintz*

Institut de Chimie de la Matière Condensée de Bordeaux, ICMCB CNRS, Université Bordeaux 1, Pessac 33608, France

\begin{abstract}
Either boehmite $\left(\gamma\right.$-AlOOH) or gibbsite $\left(\gamma-\mathrm{Al}(\mathrm{OH})_{3}\right)$ nanocrystalline thin films $(\mathrm{h} \approx 100 \mathrm{~nm})$ can be precipitated from $\mathrm{AlCl}_{3}$ solution at fixed $\mathrm{pH}$ and temperature onto different substrates. It depends on the nature of the substrate (mica flakes, $\mathrm{SiO}_{2}$ flakes, or $\alpha-\mathrm{Al}_{2} \mathrm{O}_{3}$ flakes), on their crystallographic properties (crystalline or amorphous), and on some experimental parameters (agitation rate, addition rate). According to the surface charge of the substrates, different alumina species are involved in the precipitation process. When negative charges are present on the substrate, the $\left[\mathrm{Al}_{3} \mathrm{O}(\mathrm{OH})_{3}\left(\mathrm{OH}_{2}\right)_{9}\right]^{4+}$ polycation is promoted, leading to the formation of the $\left(\mathrm{Al}_{4}\right)$ tetramer $\left(\left[\mathrm{Al}_{4} \mathrm{O}\right.\right.$ $\left.(\mathrm{OH})_{10}\left(\mathrm{OH}_{2}\right)_{5} \mathrm{I}^{\mathrm{O}}\right)$ and then to the precipitation of bohemite. When positive charges are present, a ligand bridge containing complex $\left(\left[\mathrm{Al}_{3} \mathrm{O}(\mathrm{OH})_{3}\left(\mathrm{O}_{2} \mathrm{H}_{3}\right)_{3}\left(\mathrm{OH}_{2}\right)_{9}\right]^{+}\right)$is likely favored, giving rise to hexagonal ring structures or amorphous solids that lead to the formation of gibbsite. Besides the surface effects, crystalline substrates can act as a template during precipitation of aluminum species as shown for the formation of gibbsite on muscovite. Finally, calcination at 850 $\mathrm{C}$ of boehmite samples leads to porous $\gamma-\mathrm{Al}_{2} \mathrm{O}_{3}$ layers, while calcination of gibbsite leads to $\delta-\mathrm{Al}_{2} \mathrm{O}_{3}$ layers.
\end{abstract}

\section{Introduction}

$\mathrm{M}$ ANY studies have been devoted to alumina because of its importance in industrial applications. Transition alu mina and $\alpha \mathrm{Al}_{2} \mathrm{O}_{3}$ are notably used as catalytic carriers. ${ }^{1-2} \mathrm{Alu}$ mina is also found in coatings and cosmetics as additive and substrate. ${ }^{3-6}$ The nomenclature and the relative stability of the different "alumina" species is now quite well understood. ${ }^{1,2,7-13}$ Aluminum compounds can be divided into four classes. Gibbsite $\left(\gamma \mathrm{Al}(\mathrm{OH})_{3}\right)$ and bayerite $\left(\alpha \mathrm{Al}(\mathrm{OH})_{3}\right)$ belong to the aluminum trihydroxide class. The aluminum oxide hydroxides compose a second class including the boehmite $(\gamma \mathrm{AlOOH})$ and the diaspore $(\alpha \mathrm{AlOOH})$. Transition alumina, including the $\gamma, \eta$, $\delta, \theta, \kappa, \chi$, and $\rho$ alumina, form the third class. They are ob tained from the hydrated species through thermal decompos ition. The thermal evolution of these metastable transition alumina leads to the formation of the thermodynamically stable phase of aluminum oxide: corundum $\alpha \mathrm{Al}_{2} \mathrm{O}_{3}$. The base of alu mina polymorphism has been established for a long time, ${ }^{7}$ but some additional phases could still be identified like the $\theta^{\prime}, \theta,{ }^{\prime \prime}$ and $\lambda$ phases. ${ }^{13}$

In contrast to these papers, the present study deals with alu mina as layers on ceramic substrates and will address how the

G. Franks - contributing editor

\footnotetext{
*Member, American Ceramic Society.

Author to whom correspondence should be addressed. e-mail Peter.Reynders $a$ merck.de
}

chemical composition and the morphology of "alumina" species are influenced by the presence and chemical nature of the sub strate. This question is important for the controlled and repro ducible formation of substrate based "alumina" layers, which are used in a number of industrial applications such as catalyst supports $^{1-2}$ and optical effect pigments. ${ }^{6}$ The latter, which are also called nacreous pigments, have been manufactured to imi tate the fascinating optical effect of natural pearls. ${ }^{6,14,15}$ They are composed of submicron layers deposited on a ceramic sub strate. Many products have already been developed for func tional purposes, e.g., security printing and heat management via IR reflection, and decorative purposes, e.g., cosmetics and auto motive paints. Alumina is of two fold interest: first, as a dense layer with a refractive index in a medium range to design optical multiplayer pigments, and second as a porous layer to fix func tional additives upon.

Alumina species are precipitated onto different flaky sub strates, all of which are commercially relevant for optical effect pigments. ${ }^{14}$ The phases obtained are compared with each other and to the powders generated without any substrates. The in fluence of the substrate on the precipitation of hydrated alumina is examined and a mechanism of precipitation is proposed for the different cases. The structural evolution of precipitated alu mina through heat treatment is also examined in order to design dense, respectively, porous layers as required by the different pigment applications.

\section{Experimental Procedures}

\section{(1) Powder Preparation}

The alumina layers were deposited onto different substrates via an aqueous liquid deposition process (LDP). It corresponds to the controlled precipitation of aluminum chloride within an aqueous suspension containing the substrates. The $\mathrm{pH}$ value was maintained at 6.5 by addition of an aqueous sodium hydroxide solution (16\%, Merck, Darmstadt, Germany). The temperature was maintained at $75^{\circ} \mathrm{C}$. The influence of three parameters was studied: the solution addition rate $(\mathrm{SAR} ; \mathrm{mL} / \mathrm{min})$, the agitation rate (AR rpm), and the volume of the suspension containing the substrate (VSS L). SAR corresponds to the addition rate of the $\mathrm{AlCl}_{3}$ solution in the reactor and was chosen equal to 3 or $6 \mathrm{~mL} / \mathrm{min}$. AR corresponds to the speed of the mechanical stir rer used to homogenize the suspension. In the following experi ments, AR is equal to 1000 or $1300 \mathrm{rpm}$. Finally, VSS represents the volume of the substrate suspension $(10 \mathrm{wt} \%)$ in the reactor at the beginning of the reaction. VSS is equal to 1 or $2 \mathrm{~L}$. The thickness of the layers can be controlled by varying the amount of $\mathrm{AlCl}_{3}$ solution used in the LDP. The precipitates were filtered off, washed completely with deionized water, and dried at $110^{\circ} \mathrm{C}$ for $12 \mathrm{~h}$. For the present study, a $9 \mathrm{wt} \% \mathrm{AlCl}_{3}$ solution was added until the theoretical (" $\mathrm{Al}_{2} \mathrm{O}_{3}$ "/ $/$ pigment) ratio reached 45 wt $\%$. The $\mathrm{AlCl}_{3}$ solution was prepared by dissolving the required amount of $\mathrm{AlCl}_{3}, 6 \mathrm{H}_{2} \mathrm{O}$ (Merck, purity >97\%) in 
Table I. Influence of Volume of the Substrate Suspension (VSS) on the Alumina Species Precipitated (SAR 6 and AR

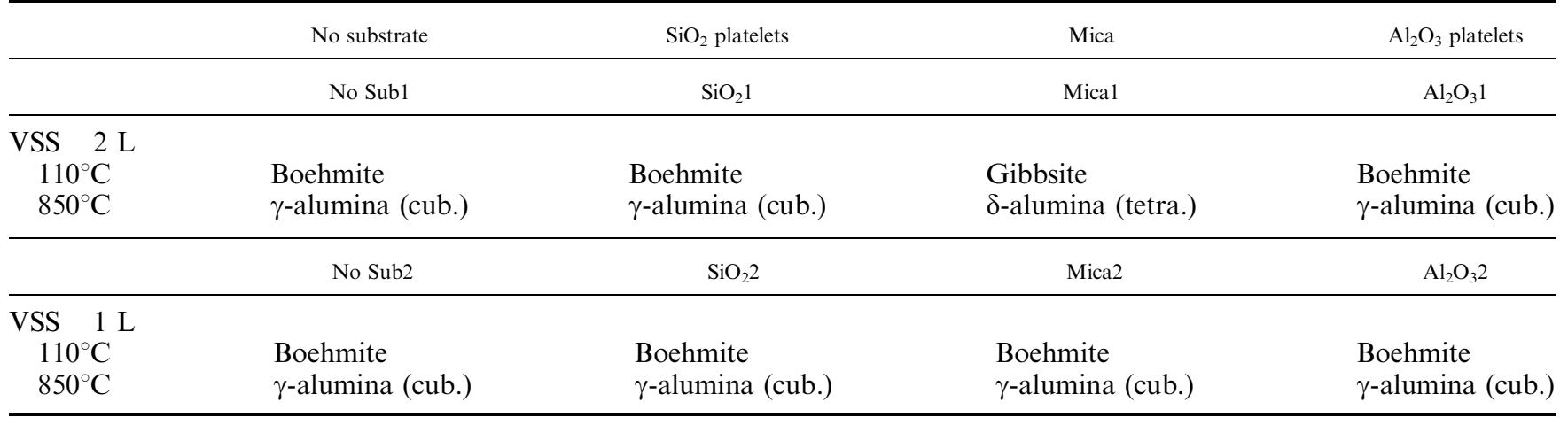

deionized water. Using the same conditions, alumina powders were precipitated without any substrate. All dried pigments were then calcined at $850^{\circ} \mathrm{C}$ under air for $30 \mathrm{~min}$. All performed ex periments are listed in Tables I, II, and III.

\section{(2) Substrates}

Three different substrates were used in this study: mica flakes (Merck, diameter $1050 \mu \mathrm{m}$, mean thickness $400 \mathrm{~nm}$ ), $\mathrm{SiO}_{2}$ flakes (Merck, diameter $1050 \mu \mathrm{m}$, thickness $450 \pm 10 \mathrm{~nm}$ ), and $\mathrm{Al}_{2} \mathrm{O}_{3}$ flakes (Merck, diameter $1050 \mu \mathrm{m}$, thickness $200 \pm 10 \mathrm{~nm}$ ). The mica used is the dioctahedral muscovite $\mathrm{KAl}_{2}$ $\left[\mathrm{AlSi}_{3} \mathrm{O}_{10}\right](\mathrm{OH})_{2} \cdot{ }^{16}$ The structure of mica muscovite is based on a three layer system that can cleave easily along the (001) plane. ${ }^{16-18}$ These planes are composed of arrangements of hexagonal rings of $\mathrm{SiO}_{4}$ tetrahedra. The surfaces of the muscovite on which aluminum is precipitated are actually oriented according to these (001) planes. The synthetic $\mathrm{SiO}_{2}$ flakes that were used are produced by a web coating process. ${ }^{6,14}$ These substrates are amorphous and present quite smooth surfaces as observed from high resolution SEM analyses. The main component of $\mathrm{Al}_{2} \mathrm{O}_{3}$ flakes is $\alpha \mathrm{Al}_{2} \mathrm{O}_{3}(99.1 \mathrm{wt} \%)$. A small amount of $\mathrm{TiO}_{2}$ is also present $(0.5 \mathrm{wt} . \%)$ as an amorphous phase. The surface of the flakes is preferentially orientated according to the (001) plane of $\alpha \mathrm{Al}_{2} \mathrm{O}_{3}$ corundum.

\section{(3) Powder Characterization}

$\mathrm{X}$ ray diffraction (XRD) patterns were taken from a $\theta / \theta$ dif fractometer (D5000, Brüker AXS GmbH, Karlsruhe, Ger many). The radiation used was $\mathrm{CuK} \alpha$. The detector was moved with a step size of $0.020^{\circ}$ in $2 \theta$ and a step time of $8 \mathrm{~s}$. Diffractograms were typically recorded in an angular range be tween $5^{\circ}$ and $80^{\circ}$ in $2 \theta$. The morphology of the particles was studied by scanning electron microscopy (SEM; Leo $1530 \mathrm{Gem}$ ini, Carl Zeiss NTS GmbH, Oberkochen, Germany). SEM was also used to measure the layer thickness on micrographs of frac tured pigments. The pigments were mixed with a lacquer and

Table II. Influence of Solution Addition Rate (SAR) on the Alumina Species Precipitated (VSS 1 and AR 1000)

\begin{tabular}{|c|c|c|c|c|}
\hline & No substrate & $\mathrm{SiO}_{2}$ platelets & Mica & $\mathrm{Al}_{2} \mathrm{O}_{3}$ platelets \\
\hline & No Sub2 & $\mathrm{SiO}_{2} 2$ & Mica2 & $\mathrm{Al}_{2} \mathrm{O}_{3} 2$ \\
\hline \multirow[t]{2}{*}{$\begin{array}{l}\mathrm{SAR} \quad 6 \mathrm{~mL} / \mathrm{min} \\
110^{\circ} \mathrm{C} \\
850^{\circ} \mathrm{C}\end{array}$} & $\begin{array}{l}\text { Boehmite } \\
\gamma \text {-alumina (cub.) }\end{array}$ & $\begin{array}{l}\text { Boehmite } \\
\gamma \text {-alumina (cub.) }\end{array}$ & $\begin{array}{l}\text { Boehmite } \\
\gamma \text {-alumina (cub.) }\end{array}$ & $\begin{array}{l}\text { Boehmite } \\
\gamma \text {-alumina (cub.) }\end{array}$ \\
\hline & No Sub3 & $\mathrm{SiO}_{2} 3$ & Mica3 & $\mathrm{Al}_{2} \mathrm{O}_{3} 3$ \\
\hline $\begin{array}{l}\mathrm{SAR} 3 \mathrm{~mL} / \mathrm{min} \\
110^{\circ} \mathrm{C} \\
850^{\circ} \mathrm{C}\end{array}$ & $\begin{array}{l}\text { Boehmite } \\
\gamma \text {-alumina } \\
\text { (cub.) }\end{array}$ & $\begin{array}{l}\text { Boehmite } \\
\gamma \text {-alumina } \\
\text { (cub.) }\end{array}$ & $\begin{array}{l}\text { Gibbsite } \\
\delta \text {-alumina } \\
\text { (tetra.) }\end{array}$ & $\begin{array}{l}\text { Boehmite/Gibbsite } \\
\gamma \text {-alumina (cub.)/ } \\
\delta \text {-alumina (tetra.) }\end{array}$ \\
\hline
\end{tabular}

Table III. Influence of Agitation Rate (AR) on the Alumina Species Precipitated (VSS 2 and SAR 6)

\begin{tabular}{ccccc}
\hline No substrate & $\mathrm{SiO}_{2}$ platelets & Mica & $\mathrm{Al}_{2} \mathrm{O}_{3}$ platelets \\
\hline No Subl & $\mathrm{SiO}_{2} 1$ & $\mathrm{Mica}_{1}$ & $\mathrm{Al}_{2} \mathrm{O}_{3} 1$ \\
\hline $\mathrm{AR} 1000 \mathrm{M}$
\end{tabular}

AR $1000 \mathrm{rpm}$

$\begin{array}{lll}110^{\circ} \mathrm{C} & \text { Boehmite } & \text { Boehmite } \\ 850^{\circ} \mathrm{C} & \gamma \text {-alumina (cub.) } & \gamma \text {-alumina (cub.) }\end{array}$

$\begin{array}{ll}\text { Boehmite } & \text { Boehmite } \\ \gamma \text {-alumina (cub.) } & \gamma \text {-alumina (cub.) }\end{array}$

Gibbsite

$\delta$-alumina (tetra.)

Boehmite

$\gamma$-alumina (cub.)

$\begin{array}{lll}\text { No Sub4 } & \mathrm{SiO}_{2} 4 & \mathrm{Al}_{2} \mathrm{O}_{3} 4\end{array}$

AR $1300 \mathrm{rpm}$

$110^{\circ} \mathrm{C}$

No Sub4

$\mathrm{SiO}_{2} 4$

$\mathrm{Al}_{2} \mathrm{O}_{3} 4$

\section{$850^{\circ} \mathrm{C}$}

$\begin{array}{ll}\text { Boehmite } & \text { Boehmite } \\ \gamma \text {-alumina } & \gamma \text {-alumina } \\ \text { (cub.) } & \text { (cub.) }\end{array}$

Boehmite/Gibbsite $\gamma$-alumina (cub.)/ $\delta$-alumina (tetra.) 


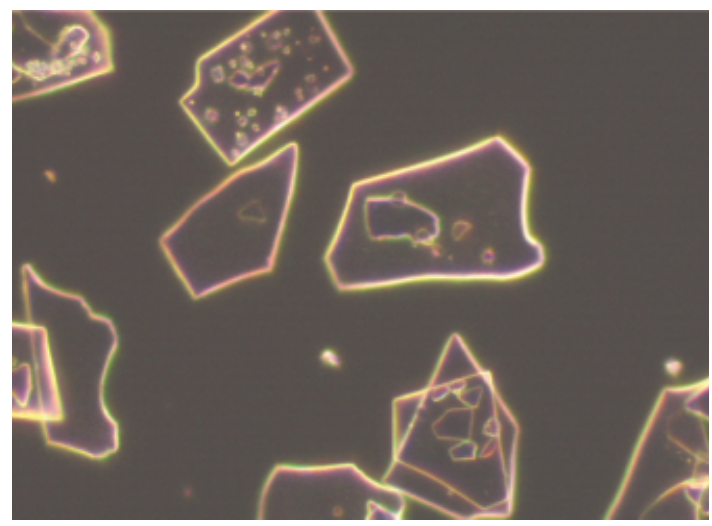

(a)

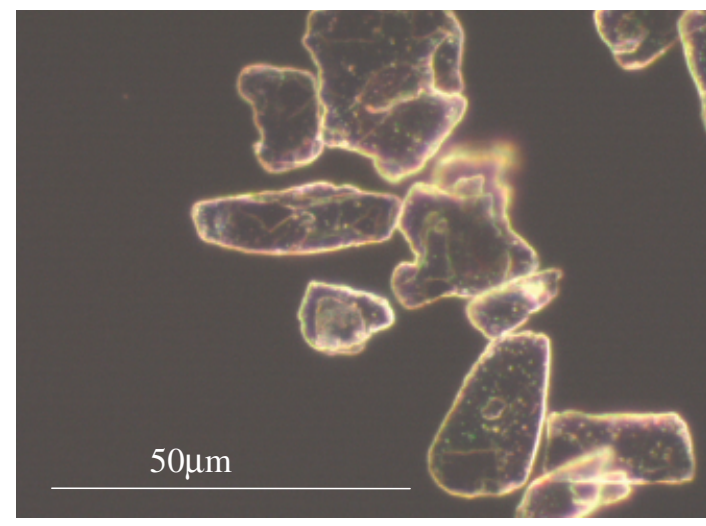

(b)

Fig. 1. Light microscopy images of (a) $\mathrm{SiO}_{2} 1$ and (b) Mical particles (reflection stage dark field).

dried. The lacquer, containing the pigments, was then broken in such a way that some of the particles were also broken, which allowed the thickness of the coated film to be measured. Light microscopy micrographs of the samples were taken using an optical microscope (Eclipse ME 600, Nikon GmbH, Düsseldorf, Germany) under reflection conditions.

\section{Results}

\section{(1) Aluminum Hydroxides and Oxide Hydroxides Precipitated Under Different Conditions}

The dried pigments were observed using light microscopy under reflection (Fig. 1). The pigments appeared transparent, which shows macroscopically the good quality of these pigments and the homogeneity of the layers.

Tables I, II, and III give the crystallographic nature of the precipitated aluminum compounds as a function of the exper imental conditions. It shows that boehmite $(\gamma \mathrm{AlOOH})$ was al ways synthesized when there was no substrate in the suspension. Boehmite was also systematically precipitated onto $\mathrm{SiO}_{2}$ flakes. Gibbsite $\left(\gamma \mathrm{Al}(\mathrm{OH})_{3}\right)$ was generally precipitated on mica. Never theless, it was also possible to obtain boehmite on mica by choosing the right parameters (Mica2). Tables I and II point out the importance of the volume of the suspension (VSS) and of the solution addition rate (SAR) on the precipitation process in the presence of mica flakes. Boehmite $(\gamma \mathrm{AlOOH})$ or a mixture of boehmite $(\gamma \mathrm{AlOOH})$ and gibbsite $\left(\gamma \mathrm{Al}(\mathrm{OH})_{3}\right)$ were synthesized on $\mathrm{Al}_{2} \mathrm{O}_{3}$ flakes. The SAR and the agitation rate (AR) param eters could determine the structure of the hydrated alumina de posited on $\mathrm{Al}_{2} \mathrm{O}_{3}$ flakes (Tables II and III). Figure 2 shows the $\mathrm{X}$ ray diffractogram of the material resulting from the pre

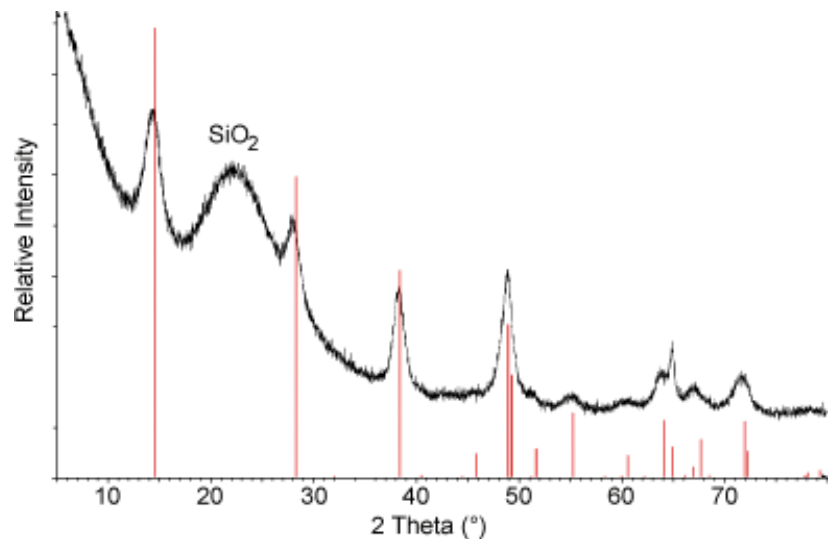

Fig. 2. $\mathrm{X}$ ray diffraction (XRD) pattern of $\mathrm{SiO}_{2} 1$ (dried state). Vertical lines correspond to the XRD pattern of boehmite $(\gamma \mathrm{AlOOH})$.

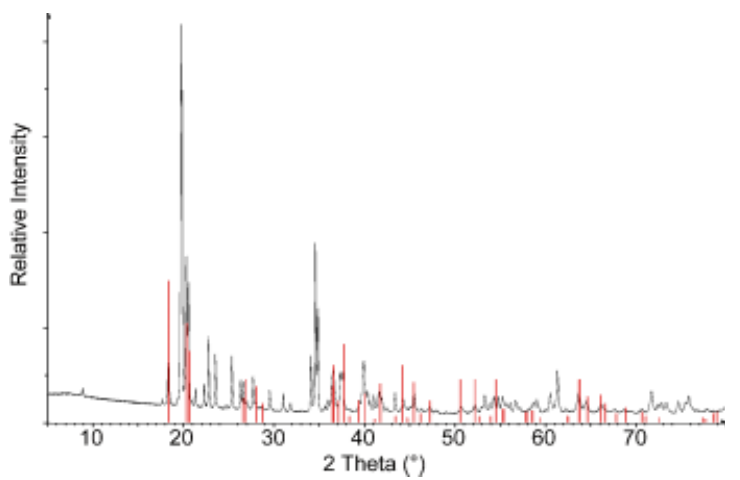

Fig. 3. X ray diffraction pattern of Mical (dried state). Vertical lines correspond to the $\mathrm{X}$ ray diffraction pattern of gibbsite $\left(\gamma \mathrm{Al}(\mathrm{OH})_{3}\right)$. Other peaks are attributed to the mica substrate.

cipitation of boehmite $(\gamma \mathrm{AlOOH})$ onto $\mathrm{SiO}_{2}$ flakes. The broad ness of the peaks, corresponding to the boehmite structure, clearly indicates the low crystallinity of this phase. Figure 3 presents the $\mathrm{X}$ ray diffractogram corresponding to the phase precipitated onto mica. The analysis of this $\mathrm{X}$ ray diffractogram is more difficult than the previous one due to the high crystal linity of mica. However, $\gamma \mathrm{Al}(\mathrm{OH})_{3}$ (gibbsite) has been identi fied. The same observations can be made for $\mathrm{X}$ ray diffractograms of products precipitated onto $\alpha \mathrm{Al}_{2} \mathrm{O}_{3}$ flakes.

SEM cross sections of Mica1 and Mica2 experiments are presented in Fig. 4. As can be seen on these micrographs, the alumina layers are precipitated quite regularly onto the mica flakes. The thickness of the dried film obtained for Mical pig ment $\left(\mathrm{h}_{\text {Mical }} \approx 100 \mathrm{~nm}\right)$ appears lower than that observed for Mica2 pigment $\left(\mathrm{h}_{\mathrm{Mica} 2} \approx 250 \mathrm{~nm}\right)$. However, the thickness value of the Mica2 layer should be considered carefully. It could be related to its porous microstructure that could be filled by the lacquer used for the cross section micrograph. The morphology of the dried layers, obtained from SEM images, is presented in Figs. 5 7. Boehmite layers exhibit a very porous and fibrillar microstructure. Those characteristics may also explain the high er thickness observed for Mica2 pigment compared with Mica1. Gibbsite layers are more compact and constituted of platelets like grains with a hexagonal shape. Concerning precursors made of gibbsite boehmite $/ \alpha \mathrm{Al}_{2} \mathrm{O}_{3}$ flakes, SEM observations show that the two precipitated phases were really separated: boehmite $(\gamma \mathrm{AlOOH})$ gives a porous layer, while gibbsite $\left(\gamma \mathrm{Al}(\mathrm{OH})_{3}\right)$ leads to platelets like grains (Fig. 7). Figure 8 shows a porous $\mathrm{AlOOH}$ layer (boehmite) largely covering the surface of $\alpha \mathrm{Al}_{2} \mathrm{O}_{3}$ platelets, whereas platelet like grains of $\mathrm{Al}(\mathrm{OH})_{3}$ (gibbsite) cover the sides of $\alpha \mathrm{Al}_{2} \mathrm{O}_{3}$ platelets. Few platelet like grains of $\mathrm{Al}(\mathrm{OH})_{3}$ could also be seen on the larger surface of the sub strate. 


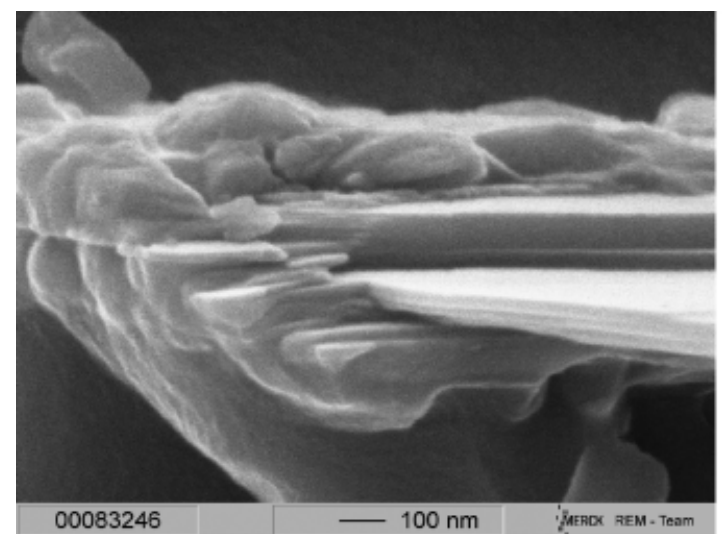

(a)

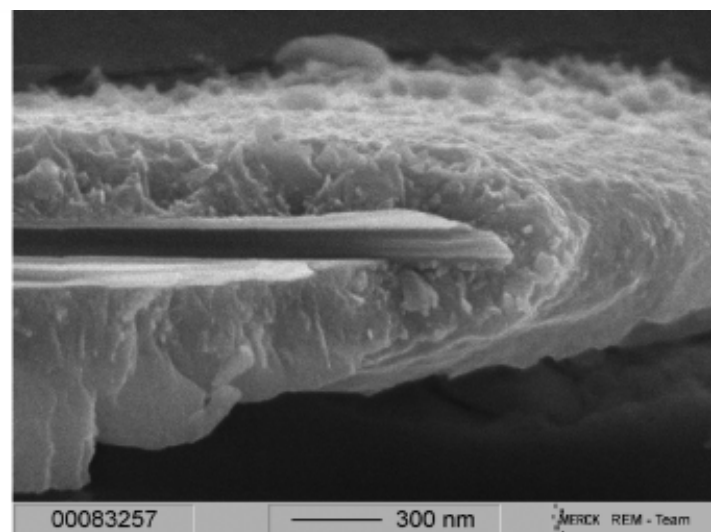

(b)

Fig. 4. Scanning electron microscopy micrographs of cross sections of (a) Mica1 film and (b) Mica2 film (dried state).
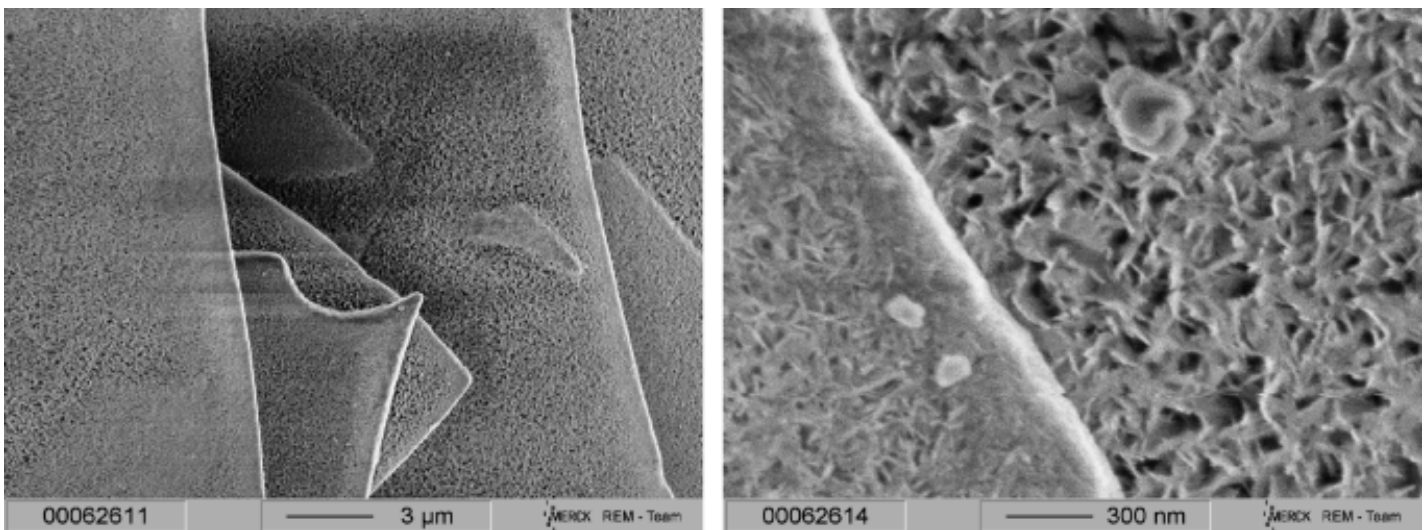

Fig. 5. Scanning electron microscopy micrographs of the surface of $\mathrm{SiO}_{2} 1$ particles (dried state).
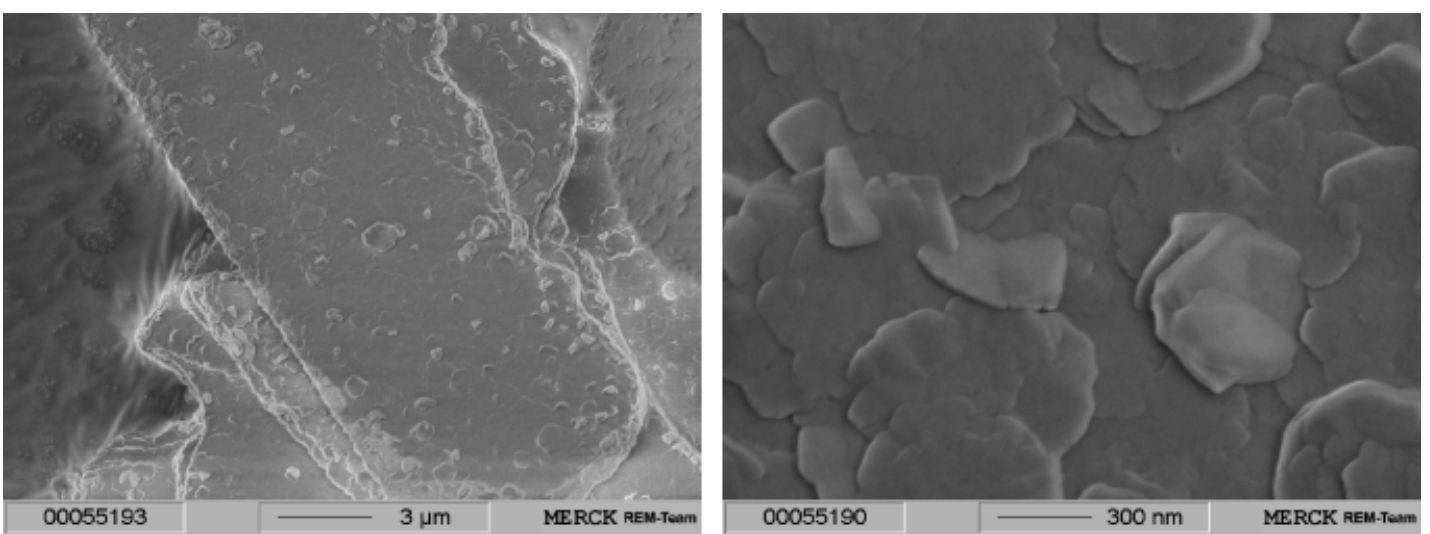

Fig. 6. Scanning electron microscopy micrographs of the surface of Mical particles (dried state).
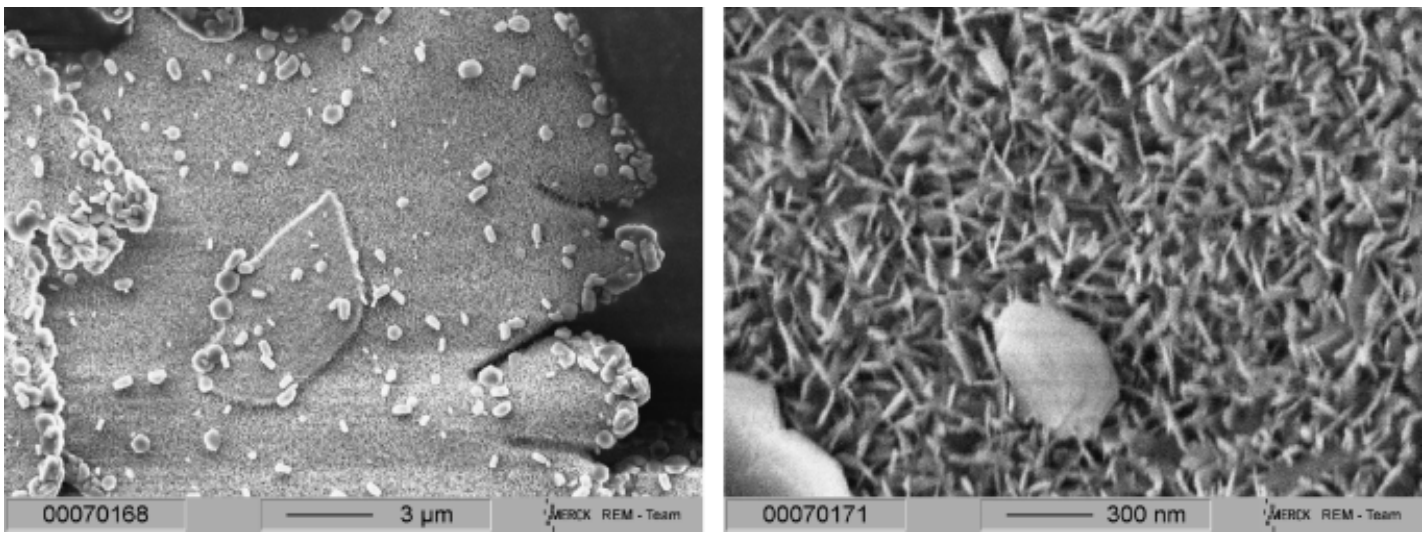

Fig. 7. Scanning electron microscopy micrographs of the surface of $\mathrm{Al}_{2} \mathrm{O}_{3} 3$ particles (dried state). 


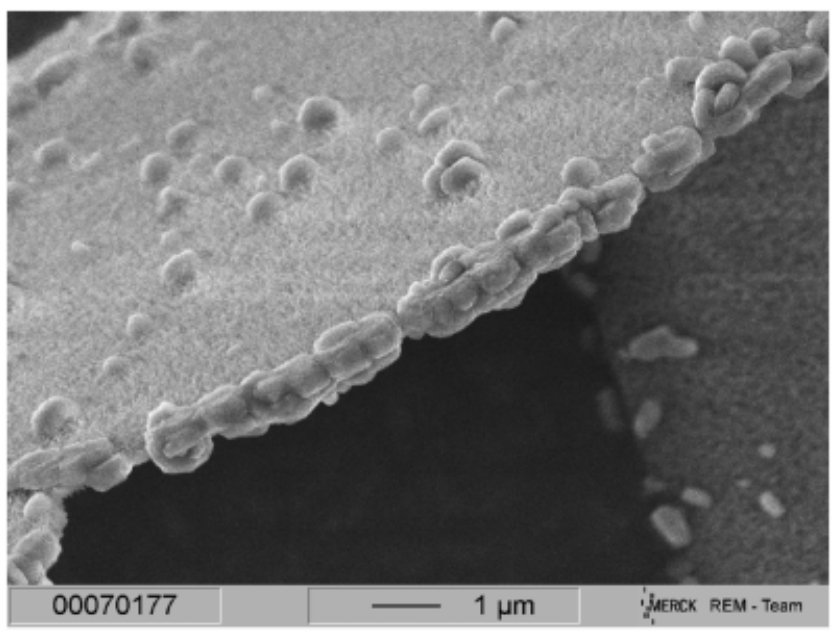

Fig. 8. Scanning electron microscopy micrograph of an alumina flake on which gibbsite grains develop from the edges.

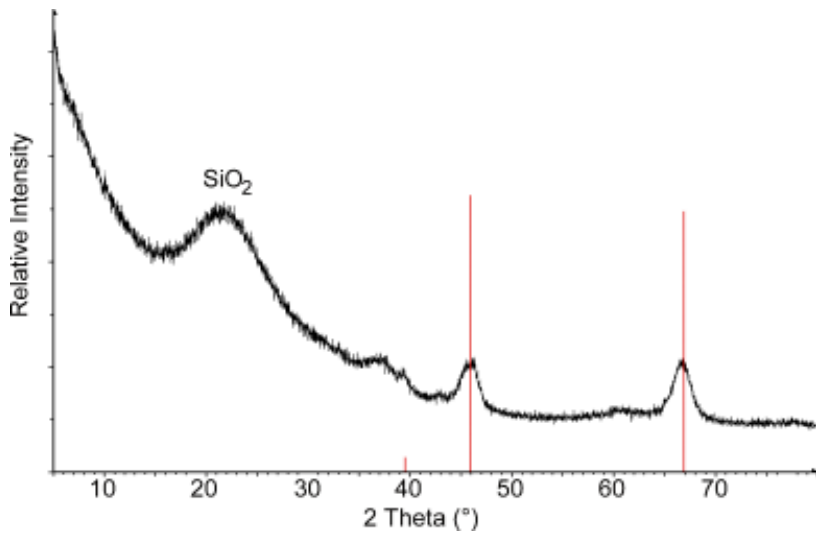

Fig. 9. $\mathrm{X}$ ray diffraction pattern of $\mathrm{SiO}_{2} 1$ after calcination at $850^{\circ} \mathrm{C}$. Vertical lines correspond to the $\mathrm{X}$ ray diffraction pattern of the cubic $\gamma \mathrm{Al}_{2} \mathrm{O}_{3}$ phase.

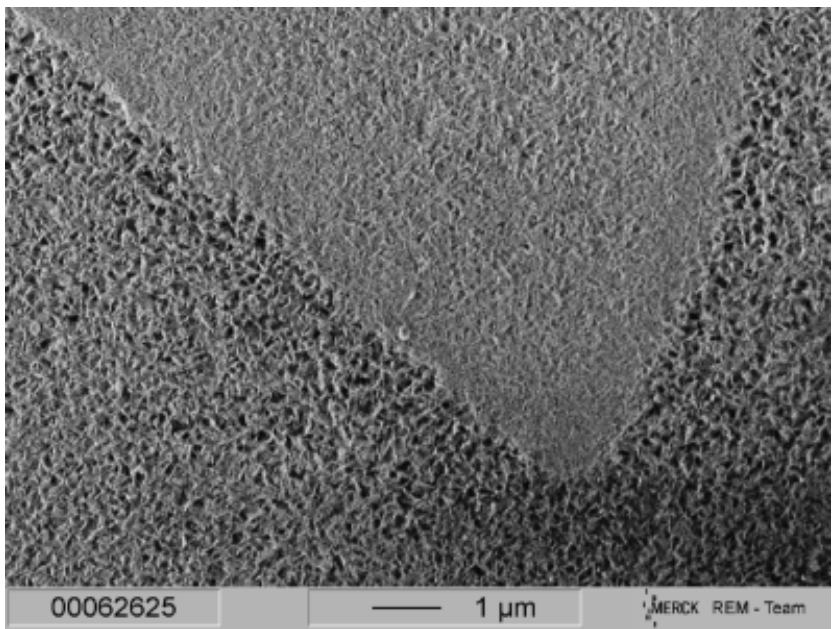

Fig. 10. Scanning electron microscopy micrograph of the surface of two $\mathrm{SiO}_{2} 1$ particles after calcination at $850^{\circ} \mathrm{C}$.

\section{(2) Thermal Evolution of the Hydrated Alumina}

Considering the calcination process that has been used, the tem perature $\left(850^{\circ} \mathrm{C}\right)$ is not high enough to enable the formation of $\alpha$ alumina. So, transition alumina are obtained. XRD patterns show that cubic $\gamma \mathrm{Al}_{2} \mathrm{O}_{3}$ is formed when the initial precipitated layer is boehmite $(\gamma \mathrm{AlOOH})$. The example of $\mathrm{SiO}_{2} 1$ pigment is

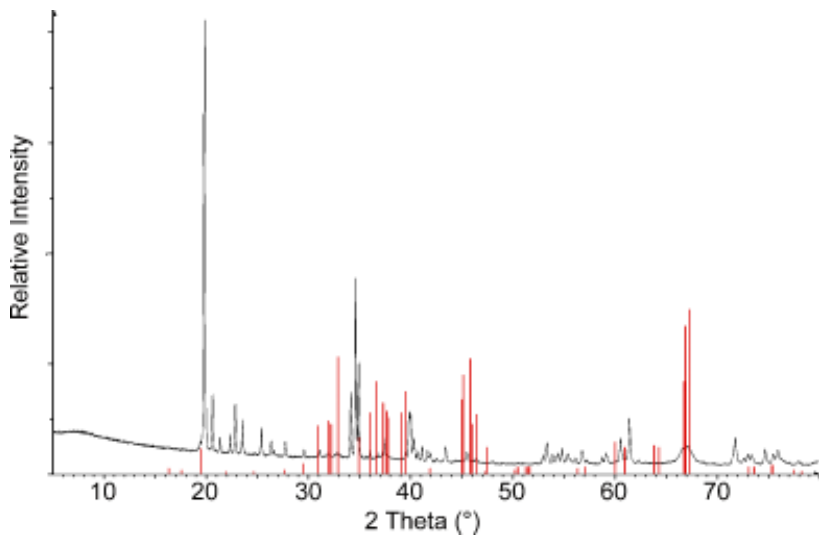

Fig. 11. $X$ ray diffraction pattern of Mical after calcination at $850^{\circ} \mathrm{C}$. Vertical lines correspond to the $\mathrm{X}$ ray diffraction pattern of the tetrago nal $\delta \mathrm{Al}_{2} \mathrm{O}_{3}$ phase. Other peaks are attributed to the mica substrate.

given in Fig. 9. The same porous morphology than that of the dried layer is obtained as illustrated by the SEM images of the top surface of $\mathrm{SiO}_{2} 1$ pigment (Fig. 10). When the precursor pig ment contains a gibbsite $\left(\gamma \mathrm{Al}(\mathrm{OH})_{3}\right)$ layer, the calcination pro cess leads to the formation of the tetragonal $\delta$ alumina. This is illustrated in Fig. 11, which presents the XRD pattern of calc inated Mica1 pigments. In that case, the calcinated alumina lay ers $\left(\delta \mathrm{Al}_{2} \mathrm{O}_{3}\right)$ are highly cracked as can be seen on the SEM images of the top surface of Mical pigment (Fig. 12).

\section{Discussion}

\section{(1) Precipitation of Aluminum Cations without Substrate}

The chemistry of $\mathrm{Al}(\mathrm{III})$ is known to be complex. Depending on the processing techniques used, different crystal structures and morphologies are generated. The kinetic and/or thermodynamic factors, as well as the solvent, are likely to affect the behavior of complexes in solution and the reaction mechanism. Different precipitation processing techniques are known ${ }^{2,18,19}$ : hydroxyla tion via the addition of a base at room temperature, hydroxy lation via addition of an aluminum salt in a base with controlled $\mathrm{pH}$, acidification of a basic aluminate solution or thermohydro lysis by heating of an acid solution of $\mathrm{Al}$ (III) ions to about $80^{\circ}$ $100^{\circ} \mathrm{C}$. In our case, an aluminum chloride solution is slowly added to an aqueous media maintained at $\mathrm{pH}=6.5$ and $\mathrm{T}=75^{\circ} \mathrm{C}$, which does not correspond exactly to the above pro cesses. Now, according to the literature, ${ }^{2,18,19} \mathrm{Al}^{3+}$ may form different types of complexes in a solution that lead to the for

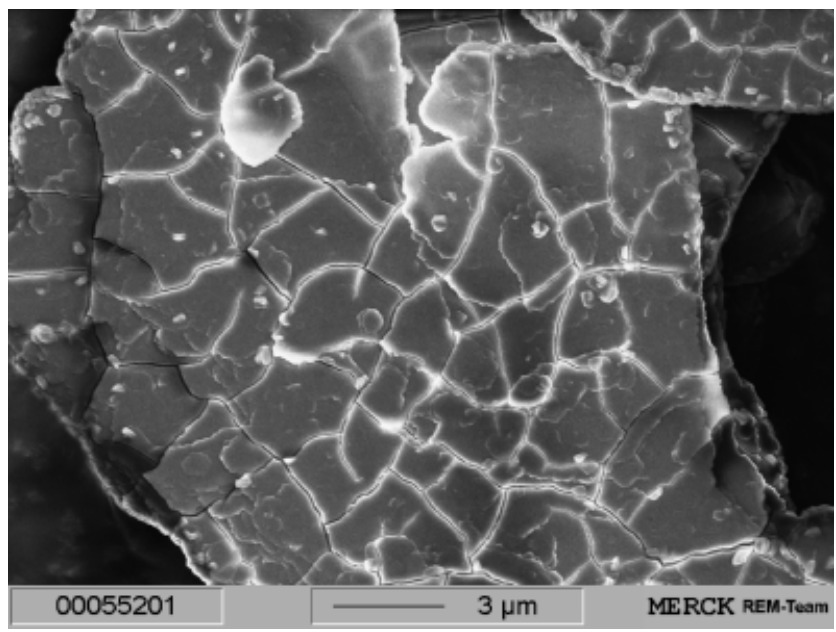

Fig. 12. Scanning electron microscopy micrograph of the surface of a Mical particle after calcination at $850^{\circ} \mathrm{C}$. 


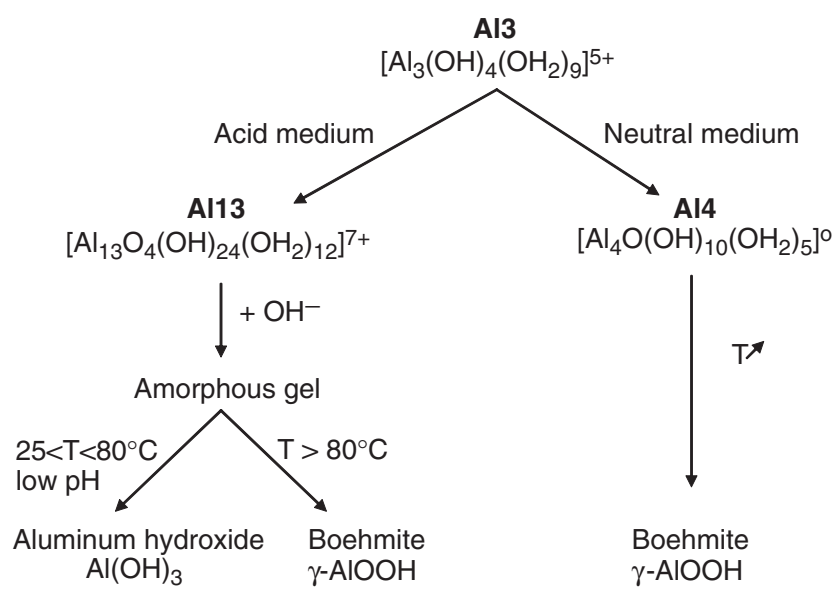

Fig. 13. Aluminum species involved in the condensation of either alu minum hydroxide $\left(\mathrm{Al}(\mathrm{OH})_{3}\right)$ or boehmite $(\gamma \mathrm{AlOOH})$, depending on the experimental conditions. ${ }^{2,18,19}$

mations of polycations which can then act as nuclei for the solid. Considering acid or neutral solutions, the species that should be considered are: $\left[\mathrm{Al}(\mathrm{OH})_{3}\left(\mathrm{OH}_{2}\right)_{3}\right]^{\mathrm{O}}$ and $\left[\mathrm{Al}_{3}(\mathrm{OH})_{4}\left(\mathrm{OH}_{2}\right)_{9}\right]^{5+}$ $\left(\mathrm{Al}_{3}\right)$. The first one, $\left[\mathrm{Al}(\mathrm{OH})_{3}\left(\mathrm{OH}_{2}\right)_{3}\right]^{\mathrm{o}}$, is involved in the con densation of boehmite $(\gamma \mathrm{AlOOH})$ when the $\mathrm{pH}$ is increased but only at room temperature. Therefore, this complex will not be considered as the starting species for the precipitation in the following discussion. The second one, $\left[\mathrm{Al}_{3}(\mathrm{OH})_{4}\left(\mathrm{OH}_{2}\right)_{9}\right]^{5+}$, is the only trimer that has been clearly identified in solution. ${ }^{20}$ Owing to its conformation, it constitutes an intermediate for the aluminum polycondensation processes. It can yield two different polycations: $\left[\mathrm{Al}_{13} \mathrm{O}_{4}(\mathrm{OH})_{24}\left(\mathrm{OH}_{2}\right)_{12}\right]^{7+}\left(\mathrm{Al}_{13}\right)$ and $\left[\mathrm{Al}_{4} \mathrm{O}(\mathrm{OH})_{10}\right.$ $\left.\left(\mathrm{OH}_{2}\right)_{5}\right]^{\mathrm{O}}\left(\mathrm{Al}_{4}\right)$, depending on the experimental conditions. This is schematically illustrated in Fig. 13.

In acidic medium, $\mathrm{Al}_{3}$ reacts with $\left[\mathrm{Al}\left(\mathrm{OH}_{2}\right)_{6}\right]^{3+}$ to give the $\mathrm{Al}_{13}$ polycation, $\left[\mathrm{Al}_{13} \mathrm{O}_{4}(\mathrm{OH})_{24}\left(\mathrm{OH}_{2}\right)_{12}\right]^{7+}$. Then, addition of a base to a solution containing $\mathrm{Al}_{13}$ leads to the formation of a translucent amorphous gel. This unstable gel gives either alu minum hydroxide $\left(\mathrm{Al}(\mathrm{OH})_{3}\right)$ when the $\mathrm{pH}$ is low and the tem perature is between $25^{\circ}$ and $80^{\circ} \mathrm{C}$ or boehmite $(\gamma \mathrm{AlOOH})$ when the temperature is higher than $80^{\circ} \mathrm{C} .^{1,2}$ In a less acidic medium and with an increase of temperature, the compact $\mathrm{Al}_{3}$ complex may evolve toward the formation of a aluminum tetramer, $\left[\mathrm{Al}_{4} \mathrm{O}(\mathrm{OH})_{10}\left(\mathrm{OH}_{2}\right)_{5}\right]^{\mathrm{o}}\left(\mathrm{Al}_{4}\right)$. These $\mathrm{Al}_{4}$ tetramers condense to form boehmite $(\gamma \mathrm{AlOOH})$ as $\mathrm{Al}_{4}$ is a good structural model for the oxyhydroxide nuclei. ${ }^{2}$ Considering that both polycations can exist under the present experimental conditions $(\mathrm{pH}=6.5$ and $\mathrm{T}=75^{\circ} \mathrm{C}$ ), the most likely species could be determined by com paring their basicity character or their electronegativity. Based on the model of partial charges, ${ }^{18}$ average electronegativity has been calculated. $\chi\left(\mathrm{Al}_{13}\right)=2.6$ and $\chi\left(\mathrm{Al}_{4}\right)=2.48$. The difference is not large but it confirms the more acidic character of the $\mathrm{Al}_{13}$ polycation. As the $\mathrm{pH}$ of the suspension was maintained at $6.5, \mathrm{Al}_{4}$ is certainly more present under these experimental conditions, leading to the formation of $\gamma \mathrm{AlOOH}$ nanoparticles. Now, even if $\mathrm{Al}_{13}$ develops within the solution, it leads to the formation of amorphous particles that can grow and crystallize on the surrounding particles, i.e., boehmite. As a matter of fact, boehmite was obtained in all our experiments (Tables I III).

\section{(2) Influence of the Substrates}

(a) Physicochemical Properties of the Oxide Surfaces. The chemical properties of the flake surfaces have to be taken into account in order to explain why gibbsite could be precipi tated in some cases, depending on the substrates present in the reactor. When an oxide is dispersed at a given $\mathrm{pH}$ in water, the nature of the surface species can be estimated from the value of the point of zero charge (PZC). For $\mathrm{pH}>\mathrm{PZC}, \quad \mathrm{O}$ groups are present, conferring a basic character to the surface, while at $\mathrm{pH}$ $\mathrm{PZC}$, no given charge is formally present. The PZC values are quite different for the oxides constituting the substrates. In the literature, the PZC of $\mathrm{SiO}_{2}$ is about two to four. The PZC of $\alpha$ $\mathrm{Al}_{2} \mathrm{O}_{3}$ particles is around eight, ${ }^{18}$ but recent studies also showed that the (001) basal plane of $\alpha \mathrm{Al}_{2} \mathrm{O}_{3}$ has lower PZC than alu mina particles. The PZC of the basal plane, which constitutes most of the surface area of $\alpha \mathrm{Al}_{2} \mathrm{O}_{3}$ platelets, is actually around five. ${ }^{21-23}$ Considering that in our experiments, the precipitation reactions are carried out at $\mathrm{pH}=6.5$, it means that the surface charge of the $\mathrm{SiO}_{2}$ flakes is negative. The surface charge of the $\mathrm{Al}_{2} \mathrm{O}_{3}$ flakes is certainly slightly negative on the basal plane but slightly positive on the side of the $\mathrm{Al}_{2} \mathrm{O}_{3}$ flakes. ${ }^{22}$ Finally, the surface charge of the mica is negative on the larger plane $\left(\mathrm{SiO}_{2}\right)$ but could be slightly positive on the side of the substrates due to the presence of $\mathrm{Al}_{2} \mathrm{O}_{3} \cdot{ }^{24}$ As a first approach, the double layer model can be used to understand the possible influence of the surface charge on the precipitated products. Counter ions can not diffuse into the first layer (Stern layer). But other species can be attracted to the surface and are able to penetrate the Stern layer and bind chemically on surface sites. This is the case for the aluminum trimer species $\left(\mathrm{Al}_{3}\right)$, mentioned previously. In order to take into account the role of surface charges of the different substrates, the chemical pathway going from $\mathrm{Al}_{3}$ to the precipi tates should be considered in a more detailed way. Under the experimental conditions of the precipitation, the $\mathrm{Al}_{3}$ trimer undergoes an intramolecular condensation according to the fol lowing reaction (Eq. (1) and Fig.14) ${ }^{18}$ :

$$
\begin{aligned}
& {\left[\mathrm{Al}_{3}(\mathrm{OH})_{4}\left(\mathrm{OH}_{2}\right)_{9}\right]^{5+}+\mathrm{H}_{2} \mathrm{O}} \\
& \quad \rightarrow\left[\mathrm{Al}_{3} \mathrm{O}(\mathrm{OH})_{3}\left(\mathrm{OH}_{2}\right)_{9}\right]^{4+}+\mathrm{H}_{3} \mathrm{O}^{+}
\end{aligned}
$$

The latter being in equilibrium with a complex containing $\left[\mathrm{H}_{3} \mathrm{O}_{2}\right]^{-}$ligand bridges (Eq. (2)):

$$
\begin{aligned}
& {\left[\mathrm{Al}_{3} \mathrm{O}(\mathrm{OH})_{3}\left(\mathrm{OH}_{2}\right)_{9}\right]^{4+}+3 \mathrm{H}_{2} \mathrm{O}} \\
& \leftrightarrow\left[\mathrm{Al}_{3} \mathrm{O}(\mathrm{OH})_{3}\left(\mathrm{O}_{2} \mathrm{H}_{3}\right)_{3}\left(\mathrm{OH}_{2}\right)_{9}\right]^{+}+3 \mathrm{H}_{3} \mathrm{O}^{+}
\end{aligned}
$$

The ligand bridge containing complex $\left[\mathrm{Al}_{3} \mathrm{O}(\mathrm{OH})_{3}\right.$ $\left.\left(\mathrm{O}_{2} \mathrm{H}_{3}\right)_{3}\left(\mathrm{OH}_{2}\right)_{9}\right]^{+}$is known to be able to react as a nucleophile ligand $\left(\mu_{3} \mathrm{O}\right.$ bridge $)$ with positive charged species, in order to

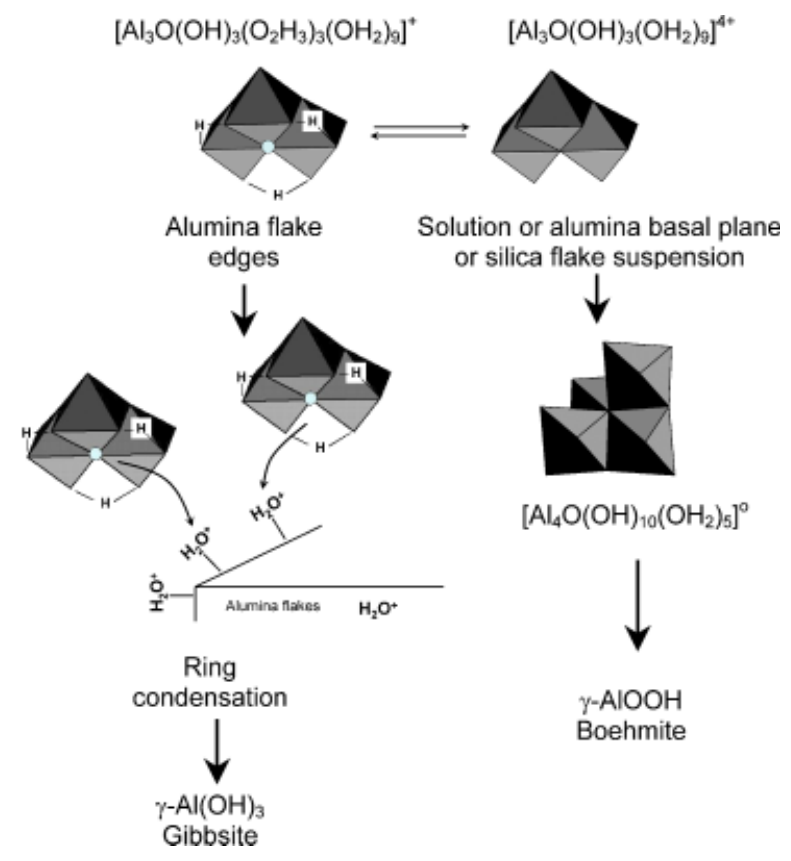

Fig. 14. Aluminum species, reagents, and products when precipitation of aluminum species occurs in the presence of different substrates. 
form the $\mathrm{Al}_{13}$ polycation ${ }^{18}$ (like the $\left[\mathrm{Al}\left(\mathrm{OH}_{2}\right)_{6}\right]^{3+}$ monomer in acidic medium). It means that the surface can play a hydrolyzing role. Depending on its acidity/basicity character, it can affect the precipitation phenomena through the evolution of a reaction (Eq. (2)). The second point to be taken into account is the crys talline properties of the substrates that can promote the growth of the initial nucleus according to the underlying lattice.

(b) Adsorption of Aluminum Species on $\mathrm{SiO}_{2}$ Flakes: The silica flakes show a basic character (negative charge sur face) at $\mathrm{pH}=6.5$. Then, the formation of the ligand bridge con taining complex $\left(\left[\mathrm{Al}_{3} \mathrm{O}(\mathrm{OH})_{3}\left(\mathrm{O}_{2} \mathrm{H}_{3}\right)_{3}\left(\mathrm{OH}_{2}\right)_{9}\right]^{+}\right)$is not promoted compared with $\left[\mathrm{Al}_{3}(\mathrm{OH})_{4}\left(\mathrm{OH}_{2}\right)_{9}\right]^{5+}$ and $\left[\mathrm{Al}_{3} \mathrm{O}(\mathrm{OH})_{3}\left(\mathrm{OH}_{2}\right)_{9}\right]^{4+}$ polycations (Fig. 14). Interactions between silica surface and these aluminum trimers will result in a deprotonation as well as intramolecular condensation (like in Fig. 13).

$$
\begin{aligned}
{\left[\mathrm{Al}_{3}(\mathrm{OH})_{4}\left(\mathrm{OH}_{2}\right)_{9}\right]^{5+} } & \rightarrow\left[\mathrm{Al}_{3} \mathrm{O}(\mathrm{OH})_{3}\left(\mathrm{OH}_{2}\right)_{9}\right]^{4+} \\
& \rightarrow\left[\mathrm{Al}_{4} \mathrm{O}(\mathrm{OH})_{10}\left(\mathrm{OH}_{2}\right)_{5}\right]^{0}
\end{aligned}
$$

It gives rise on the silica surface to the formation of the smallest stable polycation, i.e., $\mathrm{Al}_{4}$ tetramer. $\mathrm{As} \mathrm{Al}_{4}$ is the main species governing the condensation of boehmite, it should lead to the formation of this structure onto the silica flakes, which has been observed for all experiments (Tables I III). Moreover, the silica flakes are amorphous. So, they cannot induce any template effect and, in that case, only chemical effects drive the formation of the solid.

(c) Adsorption of Aluminum Species on $\mathrm{Al}_{2} \mathrm{O}_{3}$ Flakes: At $\mathrm{pH}=6.5$, the surface charge of $\mathrm{Al}_{2} \mathrm{O}_{3}$ flakes is slightly nega tive on the basal plane (PZC $\sim 5)$. The slightly negative basal plane of $\alpha \mathrm{Al}_{2} \mathrm{O}_{3}$ should promote the formation of the $\mathrm{Al}_{4}$ tet ramer, which should lead to the formation of boehmite. In fact, the formation of boehmite onto the surface of the $\mathrm{Al}_{2} \mathrm{O}_{3}$ plate lets is largely observed in all experiments. Now, it was also possible to precipitate a mixture of boehmite and gibbsite on $\alpha \mathrm{Al}_{2} \mathrm{O}_{3}$ platelets. In this case, the $\mathrm{AlOOH}$ (boehmite) is largely covering the surface of $\alpha \mathrm{Al}_{2} \mathrm{O}_{3}$ platelets, whereas grains of $\mathrm{Al}(\mathrm{OH})_{3}$ (gibbsite) cover the sides of $\alpha \mathrm{Al}_{2} \mathrm{O}_{3}$ platelets (Fig. 8). In fact, depending on their orientations, $\alpha \mathrm{Al}_{2} \mathrm{O}_{3}$ planes exhibit different acidic behavior ${ }^{21,22}$ and it is likely that the sides of the $\alpha \mathrm{Al}_{2} \mathrm{O}_{3}$ platelets exhibit a higher PZC than the basal planes of $\alpha \mathrm{Al}_{2} \mathrm{O}_{3}$ platelets insofar as they should become closer to the acidic properties of $\mathrm{Al}_{2} \mathrm{O}_{3}$ powders. Then, at $\mathrm{pH}=6.5$, the sides of $\alpha \mathrm{Al}_{2} \mathrm{O}_{3}$ platelets would present $\mathrm{OH}^{2+}$ external groups. These acid species could directly interact with the ligand bridge con taining complex $\left(\left[\mathrm{Al}_{3} \mathrm{O}(\mathrm{OH})_{3}\left(\mathrm{O}_{2} \mathrm{H}_{3}\right)_{3}\left(\mathrm{OH}_{2}\right)_{9}\right]^{+}\right)$. Therefore, equilibrium (Eq. (2)) is displaced toward the formation of $\left[\mathrm{Al}_{3} \mathrm{O}(\mathrm{OH})_{3}\left(\mathrm{O}_{2} \mathrm{H}_{3}\right)_{3}\left(\mathrm{OH}_{2}\right)_{9}\right]^{+}$, which react with the sides of the alumina flakes. Aggregation of $\left[\mathrm{Al}_{3} \mathrm{O}(\mathrm{OH})_{3}\left(\mathrm{O}_{2} \mathrm{H}_{3}\right)_{3}\left(\mathrm{OH}_{2}\right)_{9}\right]^{+}$ complexes onto the sides of alumina flakes can lead to amorph ous solids (like in the condensation of $\mathrm{Al}_{13}$ polycation) or can be structured in hexagonal rings that lead to a structure close to the lamellar structure of $\mathrm{Al}(\mathrm{OH})_{3}$ gibbsite. Now, a few platelet like grains of gibbsite $\mathrm{Al}(\mathrm{OH})_{3}$ could also be seen on the surface of $\alpha \mathrm{Al}_{2} \mathrm{O}_{3}$ platelets (Fig. 8). In fact, at $\mathrm{pH}$ 6.5, the basicity of $\alpha$ $\mathrm{Al}_{2} \mathrm{O}_{3}$ basal plane $(\mathrm{PZC} \sim 5)$ is limited and a few acidic sites can still be present at the surface of $\alpha \mathrm{Al}_{2} \mathrm{O}_{3}$ where $\mathrm{Al}(\mathrm{OH})_{3}$ grains can develop.

Nevertheless, it can be seen from experimental results (Tables II and III) that two parameters influence the crystallization of the aluminum species on $\mathrm{Al}_{2} \mathrm{O}_{3}$ flakes: the SAR and the AR. Changing these parameters allows the formation of gibbsite to be hindered or promoted. When the agitation rate is high (like in $\mathrm{Al}_{2} \mathrm{O}_{3} 4$ experiment), a better dispersion of the suspension is ob tained. As the difference between $\mathrm{pH}$ of the suspension and PZC of alumina flakes is not so large, it then helps the more acidic sites of the sides to be available for the formation of gibbsite. Conversely, at a low AR, the positive aluminum species present in the media can be preferentially adsorbed on the negative sites of the basal plane. It favors the formation of a boehmite nu cleus, which rapidly covers the $\alpha \mathrm{Al}_{2} \mathrm{O}_{3}$ platelets to the detriment of gibbsite. Concerning the SAR, an increase of this parameter leads to the formation of boehmite only. In fact, the increase of SAR leads to an increase of the metal salt concentration and of the sodium hydroxide concentration as a function of time. The ionic force of the suspension is then higher, which allows an in crease of the surface charge of the $\alpha \mathrm{Al}_{2} \mathrm{O}_{3}$ platelets. Then, the basicity of the large surfaces of $\alpha \mathrm{Al}_{2} \mathrm{O}_{3}$ platelets is enhanced, which can promote the formation of $\mathrm{AlOOH}$ on $\alpha \mathrm{Al}_{2} \mathrm{O}_{3}$ plate lets. Indeed, precipitation of alumina species onto alumina flakes under these conditions $\left(\mathrm{pH}=6.5\right.$ and $\left.T=75^{\circ} \mathrm{C}\right)$ depends on complex chemical equilibrium (condensation of ligand bridge $\mathrm{Al}_{3}$ against $\mathrm{Al}_{4}$ ). Then, the nucleation/growth processes are af fected by slight experimental variations, which explains why ei ther the mixed phases or only boehmite are obtained.

(d) Adsorption of Aluminum Species on Mica: In the case of mica, there is a charge balance around the substrates. The larger mica surface appears negative and could favor the condensation of an $\mathrm{Al}_{4}$ tetramer (like in the case of silica flakes) while the side surfaces appear positive and could preferentially imply $\left[\mathrm{Al}_{3} \mathrm{O}(\mathrm{OH})_{3}\left(\mathrm{O}_{2} \mathrm{H}_{3}\right)_{3}\left(\mathrm{OH}_{2}\right)_{9}\right]^{+}$polycations with a ligand bridge. However, for that substrate where the larger surface is oriented according to (001) planes, the $a, b$, and $\gamma$ parameters of mica are close to that of gibbsite (Table IV). Therefore, mica can act like a template during the condensation and the crystalliza tion of $\mathrm{Al}_{4}$ polycations, which favors the growth of the gibbsite phase instead of boehmite. This means that the crystalline struc ture of the mica plays a more important role than its surface charge (toward the formation of $\mathrm{Al}_{4}$ ) in the crystallization pro cess. Yet, one experiment showed that it was possible to pre cipitate some boehmite on mica (Mica2 sample: Tables I and II). In this case, the effect of the charge surface is more important than the effect of the crystalline structure. For experiment Mica2 (where VSS $=1$ ), the metal salt concentration, as a function of time, is higher than for other experiments, which corresponds to an increase of the ionic force of the suspension. For mica, the number of charged site on the flake surface is limited by their mutual repulsion. Attenuation of this repulsion by the counter ions present in the solvatation layer results in an increase of the negative surface charge of the substrates. In this case, the surface charge could really compete with the effect of the crystalline structure. Second, the alumina species remain longer in the aqueous solution without being in contact with the substrates. They have more time to transform into boehmite seeds, which are thermodynamically stable in the media. These seeds could then be physisorbed by the substrate afterwards. These experi ments show that the role of the substrates is of first importance to determine the nature of the precipitated phase. Moreover, in the case of mica, there is a competition between the crystalline effect, which promotes gibbsite, and the surface charge effect, which promotes boehmite.

Table IV. Elementary Cells Parameters Precipitated Alumi-

\begin{tabular}{|c|c|c|c|c|}
\hline & a $(\AA)$ & $\mathrm{b}(\AA)$ & c $(\AA)$ & $\gamma\left({ }^{\circ}\right)$ \\
\hline \multicolumn{5}{|l|}{$\gamma-\mathrm{AlO}(\mathrm{OH})$} \\
\hline \multicolumn{5}{|l|}{ Orthorhombic } \\
\hline JCPDS 83-2384 & 3.6936 & 12.214 & 2.8679 & \\
\hline Literature $^{13}$ & 2.861 & 3.696 & 12.233 & \\
\hline \multicolumn{5}{|l|}{$\gamma-\mathrm{Al}(\mathrm{OH})_{3}$} \\
\hline \multicolumn{5}{|l|}{ Monoclinic } \\
\hline JCPDS 01-070-2038 & 8.68400 & 5.07800 & 9.73600 & 94.54 \\
\hline Literature $^{13}$ & 8.62 & 5.06 & 9.7 & 94 \\
\hline \multicolumn{5}{|l|}{ Calcined mica muscovite } \\
\hline \multicolumn{5}{|l|}{ Monoclinic } \\
\hline Literature $^{16}$ & 5.229 & 9.076 & 20.322 & 95.74 \\
\hline \multicolumn{5}{|l|}{$\alpha-\mathrm{Al}_{2} \mathrm{O}_{3}$} \\
\hline \multicolumn{5}{|l|}{ Rhombohedral } \\
\hline JCPDS 46-1212 & 4.75870 & & 12.9929 & \\
\hline
\end{tabular}
num Species and Substrates 


\section{(3) Structural Evolution of Alumina Nanoparticles Synthesized on a Substrate}

The cubic $\gamma \mathrm{Al}_{2} \mathrm{O}_{3}$ was systematically obtained for all samples containing boehmite. These layers were porous and low crystallized, which corresponds well to other reports in the literature, ${ }^{1-2,9-12}$ mentioning that calcination of a non well crys talline "fibrillar" boehmite leads to the formation of the cubic $\gamma$ alumina between $400^{\circ}$ and $890^{\circ} \mathrm{C}$. One should note that a more crystalline boehmite would have followed another trans formation sequence: boehmite $\rightarrow$ tetragonal $\gamma$ alumina $\rightarrow$ tetragonal $\delta$ alumina. Then, the tetragonal $\delta$ alumina would have been the generated phase at $850^{\circ} \mathrm{C}^{1,12}$ which was not the case here. Conversely, thermal treatment of gibbsite layers led to the formation of tetragonal $\delta$ alumina. According to the litera ture, ${ }^{1,2,} 7-12,25$ several calcination paths starting from gibbsite exist to yield corundum $\alpha$ alumina. These paths depend on the starting material and the calcination conditions. On the one hand, calcination of gibbsite at atmospheric pressure can lead to the formation of the transition $\chi$ and $\kappa$, and then, $\alpha \mathrm{Al}_{2} \mathrm{O}_{3}$. On the other hand, another path at atmospheric pressure is known to involve first the formation of boehmite, which leads to the formation of transition tetragonal $\gamma$, tetragonal $\delta$, monoclinic $\theta$, and finally $\alpha \mathrm{Al}_{2} \mathrm{O}_{3}$. The second path occurs only if local hydrothermal conditions depending on the grain size and on the heating rate can be achieved. These hydrothermal conditions enable the transformation of gibbsite into boehmite at the be ginning of the calcination process. ${ }^{1-2,12,25}$ Our gibbsite layers are mostly constituted of nanosize gibbsite grains deposited on a rigid substrate, which can then behave locally like an autoclave and enable boehmite formation. ${ }^{2,10}$ This calcination path is sup ported by the fact that no $\kappa \quad \mathrm{Al}_{2} \mathrm{O}_{3}$ phase has been identified during heat treatment.

\section{Conclusion}

The synthesis of alumina precursors on platelets like substrates has been presented. By controlling the different precipitation parameters, it was possible to induce different alumina precur sors depending on the nature of the underlying substrate. Gibb site $\left(\gamma \mathrm{Al}(\mathrm{OH})_{3}\right)$, boehmite $(\gamma \mathrm{AlOOH})$, or a mixture of gibbsite and boehmite have been synthesized. When calcined at $850^{\circ} \mathrm{C}$, the dense pure gibbsite layers lead to a cracked tetragonal $\delta$ alumina layer. In contrast, calcination at $850^{\circ} \mathrm{C}$ of the porous boehmite leads to a crack free and porous cubic $\gamma \mathrm{Al}_{2} \mathrm{O}_{3}$. This synthesis method gives rise to the preparation of alumina layers that could be used in pigment material for functional materials.

\section{Acknowledgments}

We thank Antje Muermann (Merck KGaA) for the XRD analysis, Helmut Plamper (Merck KGaA) for the SEM micrographs, and Katsuhisa Nitta and Atsuko Nishimagi (Merck, Onahama) for the data on alumina flakes.

\section{References}

${ }^{1}$ C. Marcilly, Internal Report, Institut Français du Pétrole, Ref. no. 40 883, 1993.

${ }^{2}$ P. Euzen, P. Raybaud, X. Krokidis, H. Toulhoat, J. L. Le Loarer, J. P. Jolivet, and C. Froidefond, "Alumina"; pp. 1591677 in Hand Book of Porous Solids, Edited by F. Schüth, K. S. W. Sing, and J. Weitkamp. Wiley, Chichester, 2002.

${ }^{3}$ S. Teaney, G. Pfaff, and K. Nitta, "New Effect Pigments Using Innovative Substrates. Silica and Alumina Flakes Extend the Product Variety and Performance Range of Pearlescent Pigments," Eur. Coat. J., 4, 9096 (1999).

${ }^{4}$ N. Watanabe, K. Otsu, and H. Yoshida. J.P. Patent No. 2,005,082,441 A2, March 31, 2005.

${ }^{5}$ L. A. Kelderhouse, B. Mullaney, I. Sipsas, and I. P. Sipsas. U.S. Patent No. 5,376,698 A, December 27, 2004.

${ }^{6} \mathrm{G}$. Pfaff and P. Reynders, "Angle-Dependent Optical Effects Deriving from Submicron Structures of Films and Pigments," Chem. Rev., 99, 196381 (1999)

${ }^{7}$ H. C. Stumpf, A. S. Russel, J. W. Newsome, and C. M. Tucker, "Therma Transformations of Aluminas and Alumina Hydrates," Ind. Eng. Chem., 42, 1398 403 (1950).

${ }^{8}$ J. H. DeBoer, J. M. H. Fortuin, and J. J. Steggerda, "The Dehydration of Alumina Hydrates.II," Proc. Kon. Ned. Akad. Wet., 57, 43443 (1954).

${ }^{9}$ R. Tertian and D. Papée, "Transformations Thermiques et Hydrothermiques de ÍAlumine," J. Chim. Phys., 55, 34153 (1958).

${ }^{10} \mathrm{~J}$. Rouquerol, F. Rouquerol, and M. Ganteaume, "Thermal Decomposition of Gibbsite Under Low Pressures," J. Catal., 36, 99110 (1975).

${ }^{11}$ S. J. Wilson and J. D. C. Mc Donnel, "A Kinetic Study of the System $\gamma$ - $\mathrm{AlOOH} / \mathrm{Al}_{2} \mathrm{O}_{3}, "$ J. Solid State Chem., 30, 31522 (1979).

${ }^{12} \mathrm{~K}$. Wefers and C. Misra, "Oxides and Hydroxides of Aluminum"; Alcoa Technical Paper no. 19, revised, Alcoa Laboratories, Pittsburgh, 1987.

${ }^{13}$ I. Levin and D. Brandon, "Metastable Alumina Polymorphs: Crystal Structures and Transitions Sequences," J. Am. Ceram. Soc., 81 [8] 19952012 (1998)

${ }^{14}$ F. J. Maile, G. Pfaff, and P. Reynders, "Effect Pigments Past, Present, and Future," Prog. Org. Coat., 54, 1503 (2005).

${ }^{15}$ R. Glausch, M. Kieser, R. Maisch, G. Pfaff, and J. Weitzel, Special Effect Pigments. Ulrich Zorll, Hannover, 1998.

${ }^{16} \mathrm{~V}$. Hildenbrand, "Untersuchungen an dünnen Titandioxid- und Eisenoxidschichten auf verschiedenen Substraten (Investigation of Thin Titanium Dioxide Films and Iron Oxide films Deposited on Different Substrates)"; Ph.D. thesis, Technischen Hochschule, Darmstadt, Germany, 1995.

${ }^{17}$ Y. Kuwahara, "Muscovite Surface Structure Imaged by Fluid Contact Mode AFM," Phys. Chem. Minerals, 26, 198 (1999).

${ }^{18}$ J. P. Jolivet, Metal Oxide Chemistry and Synthesis From Solution to Solid State. Wiley, Chichester, 2000.

${ }^{19}$ M. Henry, J. P. Jolivet, and J. Livage, "Aqueous Chemistry of Metal Cations: Hydrolysis, Condensation, and Complexation," Struct. Bonding, 77, 153206 (1992).

${ }^{20}$ P. L. Brown, R. N. Sylva, G. E. Batley, and J. Ellis, "The Hydrolysis of Metal Ions. Part 8. Aluminium (III)," J. Chem. Dalton Trans., 196770 (1985).

${ }^{21}$ G. V. Franks and L. Meagher, "The Isoelectric Points of Sapphire Crystals and Alpha-Alumina Powder," Colloids Surf. A: Physicochem. Eng. Aspects, 214, 99110 (2003).

${ }^{22}$ R. J. Kershner, J. W. Bullard, and M. J. Cima, "Zeta Potential Orientation Dependence of Sapphire Substrates," Langmuir, 20, 4101018 (2004).

${ }^{23}$ M. Kosmulski, "pH-Dependent Surface Charging and Points of Zero Charge III. Update," J. Colloid Interface Sci., 298, 73041 (2006).

${ }^{24}$ P. Reynders, "Titanium Dioxide: Precipitation and Crystal Growth"; unpublished results, 1996.

${ }^{25}$ B. Ollivier, R. Retoux, P. Lacorre, D. Massiot, and G. Férey, "Crystal Structure of K-Alumina: An X-ray Powder Diffraction, TEM and NMR Study," J. Mater. Chem., 7, 104956. 